\title{
Brain Stem
}

National Cancer Institute

\section{Source}

National Cancer Institute. Brain Stem. NCI Thesaurus. Code C12441.

Three sections, the midbrain, pons and medulla oblongata, that are located at the base

of the brain. The brain stem regulates the central nervous system, and is vital as a

conduit for motor and sensory innervations. 